\title{
Three-trial sequences of reward magnitudes with odor cues maximized
}

\author{
RICHARD A. BURNS \\ Georgia Southwestern College, Americus, Georgia 31709 \\ and \\ ROGER L. THOMAS and STEPHEN F. DAVIS \\ Emporia State University, Emporia, Kansas 66801
}

\begin{abstract}
Albino rats were trained in a straight runway for three trials on each of 24 days. Five pellets were received on the third trial of each day, whereas the amounts of Trials 1 and 2 were either 20 or 0 pellets. Whether the daily sequence was $20-0-5$ or $0-20-5$ was determined by pseudorandom orders. To maximize odor cues, animals were run in rotation, with every rat receiving the same reward sequence within a day. The data during asymptotic performance shows stronger evidence of the control of running by nonreward odor when nonreward was the Trial 1 outcome than when nonreward was the Trial 2 outcome. There was no evidence for differential control of performance by odor cues when the trial outcome was 20 pellets as opposed to 5 pellets. The findings are discussed in relation to other sources of mediation of patterned running that were controlled in the present design.
\end{abstract}

The spate of experimental investigations in the last few years concerning sequences of reward magnitudes, triggered most likely by Capaldi's $(1967,1971)$ renovation of the Hull-Sheffield hypothesis, has furnished reasonably clear evidence of the operation of the Hull-Sheffield mechanisms. That aftereffects, stimulus residuals, or decaying neural traces of reward come to control rat performance may be more clearly established (e.g., Tyler, Wortz, \& Bitterman, 1953) than control by the corresponding memorial reinstatement mechanism is a common view (Gonzalez \& Bitterman, 1969). There is reasonably good evidence now for reinstatement as well (Jobe, Mellgren, Feinberg, Littlejohn, \& Rigby, 1977).

A closer look at some of the reward-sequence experiments, however, easily raises some other (besides aftereffects and memories) possibilities for control of performance under these sequences. One alternative is the differential reinforcement of specific trial stimuli, stimulus events that are different from trial to trial but that are not generated by reward per se (Burns, DeHart, \& McRae, 1980). A second possibility is conceptual rule learning: The animal learns something about the reward sequence as a whole and fits it into some sort of cognitive rule, "greater than" or "less than," for example (Hulse

This research was supported, in part, by a grant from the Charles L. Mix Memorial Foundation through the Department of Psychology of Georgia Southwestern College to the first author and a grant from the Research and Creativity Committee of Emporia State University to the third author. Portions of this paper were presented at the annual meeting of the Southern Society for Philosophy and Psychology, Louisville, Kentucky, 1981.
\& Dorsky, 1979). A third possibility, the one of concern for the present experiment, is the differential control of performance by odors left behind by conspecifics in the same experimental conditions (e.g., Davis, Prytula, \& Voorhees, 1979). The experiment to be reported here was designed to study rat performance with three-trial sequences of reward magnitudes when aftereffects, memories, trial stimuli, and rule learning were not possible sources of control.

\section{METHOD}

\section{Subjects}

Thirteen 90-day-old male Holtzman rats served as subjects. All subjects were housed in individual cages with water freely available. The subjects were placed on food deprivation and maintained at $85 \%$ of their free-feeding body weights 1 week prior to the start of pretraining.

\section{Apparatus}

Experimental testing took place in a single straight runway $(11.43 \mathrm{~cm}$ wide $\times 12.70 \mathrm{~cm}$ high) having a gray startbox $(30.44 \mathrm{~cm})$, black run section $(91.44 \mathrm{~cm})$, and black goalbox $(30.44 \mathrm{~cm})$ Masonite guillotine doors separated the startbox and goalbox from the run section. Raising the start door activated a digital timer (Lafayette, Model 54030). Interrupting a photobeam located $15.24 \mathrm{~cm}$ beyond the start door stopped the first timer (start time) and activated a second timer. Interrupting a second photobeam $76.20 \mathrm{~cm}$ beyond the first beam stopped the second timer (run time) and started a third timer. Interrupting a third photobeam located $5.08 \mathrm{~cm}$ in front of a recessed goal cup stopped the third timer (goal time). The entire apparatus was covered with a thin sheet of transparent plastic to prevent the dissipation of odors during testing.

\section{Procedure}

Prior to pretraining, the subjects were each randomly assigned a number (1-13) and were run in this sequence on all days of 
experimental testing. A pretraining period of 4 days immediately preceded the start of runway training. On Pretraining Days 1 and 2 , all subjects were handled and tamed for 1 min each. On the last 2 days of pretraining, each subject received a 5-min exploration period in the unbaited apparatus. All subjects received habituation to the 45-mg Noyes reward pellets in the home cage on all days of pretraining.

During experimental testing, each subject received three trials on each of the $\mathbf{2 4}$ days of runway training. The amount of reward on the third trial of each day was five 45-mg Noyes pellets. The amounts administered on Trials 1 and 2 were either 20 pellets or 0 pellets. Whether the daily sequence was $20-0-5$ or $0-20-5$ was determined by pseudorandom orders so that a block of 6 days contained 3 days of each sequence and a given sequence could occur on no more than 2 consecutive days. Animals were run in rotation (1-13), with every rat receiving the same reward sequence within a day, a procedure that maximizes odor cues correlated with reward/nonreward events (see Ludvigson \& Sytsma, 1967).

\section{RESULTS}

Prior to analysis and graphing, all latencies were reciprocated and multiplied by the appropriate constant to yield speed scores in meters per second. As differential responding was shown only in the goal measure, only these results will be considered.

In Figure 1 are plotted the mean goal speeds in meters per second for the last 12 days of the experiment (the point at which differential responding had been established). Each data point is a trial mean. That the main effect of days was not reliable $(\mathrm{F}<1)$ suggests asymptotic performance. The main effect of trials $[F(2,420)=4.78, p<.01]$ and the interaction of trials with days $[\mathrm{F}(22,420)=2.57, \mathrm{p}<.01]$ were both significant. The Newman-Keuls procedure was employed to evaluate contrast effects, and it indicated that speeds to the 0-pellet condition were significantly slower than speeds to the other conditions on Days 13, 15, and $16(\mathrm{p}<.05)$ and Days 19, 21, and $24(\mathrm{p}<.01)$. No other contrast effects yielded significance.

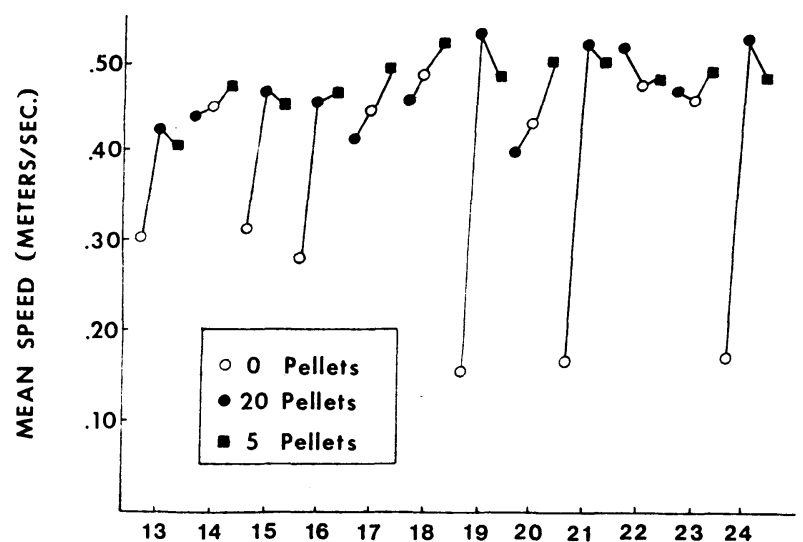

DAYS

Figure 1. Mean goal speeds (in meters per second) for 0-, 20-, and 5-pellet trials for the last 12 days of training.

\section{DISCUSSION}

Because the sequences 20-0-5 and 0-20-5 have only one reward magnitude element (five pellets) that appears consistently in a set trial position, trial stimuli as potential sources of the control of performance are a possibility only for Trial 3. No differential performance developed on Trial 3. There is also, because of the sequences employed, no consistent relationship between the aftereffects or memories of reward events and the subsequent amount of reward. Any differential performance, for that reason, cannot be the product of conditioned aftereffects or memories. Hulse (Hulse, 1980; Hulse \& Dorsky, 1977, 1979) has been unclear as to the conditions that are necessary for rule learning to occur (see Capaldi, Verry, \& Davidson, 1980), but it seems reasonable to assume that the sequences in the current experiment are not amenable to the application of any sort of consistent rule. Differential performance in these sequences cannot be the consequence of rule learning.

Running slower to the 0-reward element, a phenomenon sometimes called tracking, appeared clearly in this experiment when the 0 -reward element was delivered on Trial 1 but not when it was delivered on Trial 2. It seems plain that this tracking is best understood as the result of conspecific odors, optimized as differential cues for reward amount in this study by the rotational running procedure. Of course, the demonstration of odor-controlled tracking here illustrated the importance of evaluating the influence of odors in other "tracking" investigations-not yet a popular practice.

Why the 0-reward element did not generate tracking on Trial 2 in the present three-trial sequences is an unanswered question. However, one might offer the following speculations. There is a tendency for rats to run faster on the second trial of a training session than on the first. This tendency can be shown to be unrelated to reward amount with appropriate controls, lacking in the present experiment, and could be called warm-up. In the 20-0-5 sequence, tendencies for warm-up and tracking are antagonistic. They are, conversely, complementary for the $0-20-5$ sequence. An expectation based on this notion would be that tracking should appear on Trial 2 as training is extended and, as a result, warm-up is reduced. A hint toward Trial 2 tracking appears in the present data, not of course in a statistically reliable fashion, on Days 22 and 23, on which the 0-reward mean was lower than the other two and 0 reward was the Trial 2 element. Those are the only such instances, occurring in the last 3 days of training, in the entire experiment.

The third, and perhaps the most interesting, aspect of the present results is that differential performance did not develop for the 20- and 5-pellet elements. There has been a growing tendency for researchers (Collerain, 1978; Collerain \& Ludvigson, 1972, 1977) to associate the odors that have been shown to influence performance with frustration (Amsel, 1958, 1967). If odors are "frustrative odors," then their influence should be evident in any situation that is frustrating (according, of course, to the theory). That makes odors a powerful tool for theoretical assessment. But frustration is assumed, by Amsel, to appear any time there is a discrepancy between anticipated and encountered reward events. The present findings, coupled with those of a recent set of experiments (Davis, Whiteside, Bramlett, \& Petersen, in press), suggest that such "frustrative" or nonreward odors are exuded when strict nonreward is encountered (the 0-pellet condition), but not under conditions of reward contrast (the 5-pellet vs. 20-pellet condition in the present experiment).

\section{REFERENCES}

Amsel, A. The role of frustrative nonreward in noncontinuous reward situations. Psychological Bulletin, 1958, 55, 102-119.

Amsel, A. Partial reinforcement effects on vigor and persistence. In K. W. Spence \& J. T. Spence (Eds.), The psychology of 
learning and motivation: Advances in research and theory (Vol. 1). New York: Academic Press, 1967.

Burns, R. A., DeHart, P. J., \& McRae, H. L. Random and fixed two trial sequences of reward magnitudes. Bulletin of the Psychonomic Society, 1980, 16, 291-294.

CAPAldi, E. J. A sequential hypothesis of instrumental learning. In K. W. Spence \& J. T. Spence (Eds.), The psychology of learning and motivation (Vol. 1). New York: Academic Press, 1967.

Capaldi, E. J. Memory and learning: A sequential viewpoint. In W. K. Honig \& P. H. R. James (Eds.), Animal memory. New York: Academic Press, 1971.

Capaldi, E. J., Verry, D. R., \& Davidson, T. L. Why rule encoding by animals in serial learning remains to be established. Animal Learning \& Behavior, 1980, 8, 691-692.

Collerain, I. Frustration odor of rats receiving small numbers of prior rewarded running trials. Journal of Experimental Psychology: Animal Behavior Processes, 1978, 4, 120-130.

Collerain, I. J., \& Ludvigson, H. W. Aversion of conspecific odor of frustrative nonreward in rats. Psychonomic Science, 1972, 27, 54-56.

Colle rain, I. J., \& Ludvigson, H. W. Hurdle-jump responding in the rat as a function of conspecific odor of reward and nonreward. Animal Learning \& Behavior, 1977, 5, 177-183.

Davis, S. F., Prytula, R. E., \& Voorhees, J. W. Odor-donor cue control of runway performance: A further examination. Bulletin of the Psychonomic Society, 1979, 13, 141-144.

Davis, S. F., Whiteside, D. A., Bramlett, J. A., \& Petersen,
S. H. Odor production and utilization under conditions of nonreward and small reward. Learning and Motivation, in press.

Gonzalez, R. C., \& Bitterman, M. E. Spaced-trials partial reinforcement as a function of contrast. Journal of Comparative and Physiological Psychology, 1969, 67, 94-103.

Hulse, S. H. The case of the missing rule: Memory for reward vs. formal structure in serial-pattern learning by rats. Animal Learning \& Behavior, 1980, 8, 689-690.

Hulse, S. H., \& Dorsky, N. P. Structural complexity as a determinant of serial pattern learning. Learning and Motivation, 1977, 8, 488-506.

Hulse, S. H., \& Dorsky, N. P. Serial pattern learning by rats: Transfer of a formally defined stimulus relationship and the significance of nonreinforcement. Animal Learning \& Behavior, 1979, 7, 211-220.

Jobe, J. B., Mellgren, R. L., Feinberg, R. A., Littlejohn, R. L., \& RIGSBY, R. L. Patterning, partial reinforcement, and n-length effects at spaced trials as a function of reinstatemen of retrieval cues. Learning and Motivation, 1977, 8, 77-97.

Ludvigson, H. W., \& Sytsma, D. The sweet smell of success: Apparent double alternation in the rat. Psychonomic Science, 1967, 9, 283-284.

Tyler, D. W., Wortz, E. C., \& Bitterman, M. E. The effect of random and alternating partial reinforcement on resistance to extinction in the rat. American Journal of Psychology, 1953, 66, 37-65.

(Received for publication May 22, 1981.) 